\title{
What is the effect of advanced diagnostic methods on sensitivity and survival in the multiple breast cancers? A systematic analysis and comparison
}

\author{
Hasan Zafer Acar ${ }^{1}$, Nazmi Ozer ${ }^{2}$ \\ ${ }^{1}$ Professor, Department of General Surgery, Faculty of Medicine, Girne American University, 99428, Kyrenia, Cyprus, \\ ${ }^{2}$ Professor, Department of Biochemistry, Faculty of Pharmacy, Girne American University, 99428, Kyrenia, Cyprus
}

The sensitivities of the advanced diagnostic methods appear to be higher than the conventional methods and do have the potential to prolong survival, in multiple (multifocal and multicenter) breast cancers. Thus, the aim of this study is to compare the sensitivities of advanced and conventional diagnostic methods and to reveal their effects on survival. The studies published about diagnosis and treatment methods in multiple breast cancer in literature were searched, analyzed, and the sensitivities obtained with advanced and conventional diagnostic methods were compared, and the results were evaluated statistically. The sensitivity obtained with the advanced diagnostic methods in multiple breast cancers was found to be significantly higher than the conventional methods $(p<0.05)$. The high sensitivities obtained with advanced diagnostic methods were found to have a high potential for survivial prolongation in multiple breast cancers. The use of advanced diagnostic methods in breast cancer screening programs, the investigation of tumor foci with molecular methods, increases the rate of diagnosis in multiple breast cancers. In the treatment of multiple breast cancers, a personalized treatment plan is made with the diagnosis of the molecular structure of the tumor foci. Thus, the recurrence rates are reduced, the survival is prolonged.

Key words: Multiple breast cancer; Sensitivity; Diagnosis; Treatment

\section{Access this article online}

\section{Website:}

http://nepjol.info/index.php/AJMS DOI: 10.3126/ajms.v12i7.34352

E-ISSN: 2091-0576

P-ISSN: 2467-9100

Copyright (c) 2021 Asian Journal of Medical Sciences

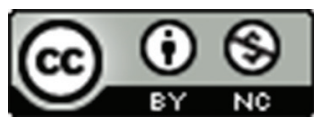

This work is licensed under a Creative Commons Attribution-NonCommercial 4.0 International License.

\section{INTRODUCTION}

Multiple breast cancers (MBC) occur quite frequently. In a study conducted by Badillo et al., it was reported that in 22 studies comprising 67,557 women multifocality was found as 9,5\%. ${ }^{1}$ MBCs may show different molecular structure, clinical course, different prognosis compared to unifocal breast cancers (UBC). Molecular tumoral heterogeneity is observed in MBCs and they may exhibit different biological behaviors compared to tumors in homogeneous molecular structure. Accordingly, the rate of survival in MBCs may differ from UBCs. Therefore, it is very important to make a molecular diagnosis for every cancer focus in MBCs.
The conventional diagnostic methods (CDM) for screening in BC are ultrasonography (USG) and mammography (MG). ${ }^{2}$ Advanced diagnostic methods (ADM) are generally utilized in a limited number of patient groups, such as BC cases under follow-up. Noninvasive ADMs used to reveal the tumor foci in MBCs are; magnetic resonance imaging (MRI), ${ }^{3}$ diffusion weighted imaging $\mathrm{MRI},{ }^{4}$ contrast enhanced MG, contrast enhanced MRI, ${ }^{5}$ magnetic resonance $M G,{ }^{6}$ micro-computer tomography (micro-CT), ${ }^{7}$ digital breast tomosynthesis with 3-D multi-leison channellized hotelling observer technique, ${ }^{8}$ dynamic contrast enhanced breast MRI.

Invasive ADMs used to reveal the molecular structure of the tumor in MBCs are; expression of miRNAs (miR-429, 
miR-182-5p, miR-96-5p) in tissue, ${ }^{10}$ antigen $\mathrm{Ki}-67$ (encoded by MK167 gene), ${ }^{11}$ expression of long non-coding RNAs in tissue (C19orf33, C3orf52, C15orf48, C4orf19), ${ }^{12}$ BRCA2 mutation carrier, ${ }^{13}$ ErbB2 expression, ${ }^{14}$ Vit-D receptor, ${ }^{15}$ differential expression of ABCC11 and ABCB5 genes, ${ }^{16}$ many other gene expression profiles. ${ }^{17}$

ADMs in MBCs have a high potential to increase sensitivity, and thus prolonged survival. The aim of this study is to compare the sensitivity of CDMs and ADMs in MBCs and to reveal the effects of ADMs on survival.

\section{MATERIALS AND METHODS}

The studies published about the diagnosis and treatment methods in MBCs (Table 1) were searched, analyzed, sensitivity rates obtained with advanced $(\mathrm{GpA})^{3-6,9}$ and conventional $(\mathrm{GpB})^{2}$ diagnostic methods were compared, and the results were evaluated statistically.

The criteria for inclusion of studies using ADM and CM in diagnosis of MBCs in our study are as follows:

1. The study was carried out in MBCs,

2. The use of noninvasive methods that can be used as screening tests,

3. The number of samples in the studies carried out is high and specific,

4. The work done has been done in the last 10 years.

Using these filtration criteria: Google Scholer, Scopus, Pubmed, ScienceOpen, BioMed Central, Academic Index, and relevant publications were included in our study.

SPSS (Statistical Package for the Social Sciences) 23.0 package program was used for statistical analysis of the data. Categorical measurements were summarized as numbers and percentages, while continuous measurements were summarized as mean and standard deviation and the range, minimum-maximum were also given where necessary. Shapiro-Wilk test was used to determine whether the parameters in the study showed normal distribution. In comparing the continuous measurements between the groups, the distributions were checked and the Mannwhitney $\mathrm{U}$ test was used in those which did not show normal distribution. Statistical significance level was taken as 0.05 in all tests.

\section{RESULTS}

Table 1 shows the sample numbers, diagnostic method, years of study, and ethnicity in the studies included in our study.

The comparision of the percent sensitivities of ADMs $(\mathrm{GpA})$ and CDMs $(\mathrm{GpB})$ is shown in Figure 1. The sensitivities obtained with ADMs in MBCs was significantly higher $(\mathrm{p}<0.05)$ compared to CDMs (Table 1$)$.

The forest plot view of the sensitivity rates obtained by $\mathrm{ADM}$ and $\mathrm{CM}$ diagnostic methods in MBC cases is shown in Figure 2.

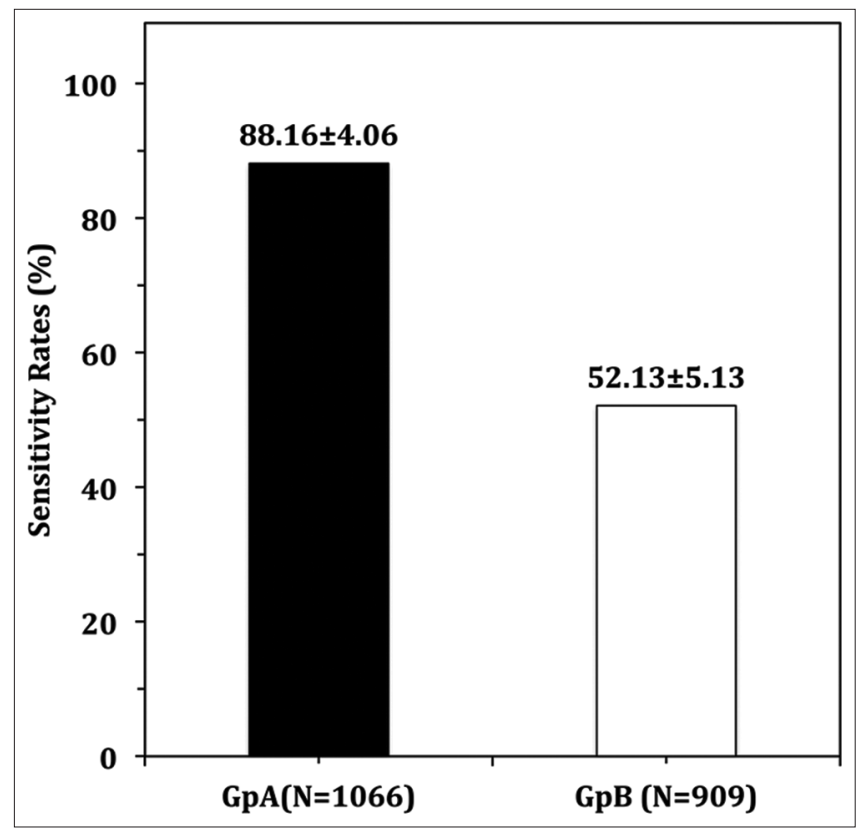

Figure 1: The comparison of the percent mean sensitivities of advanced diagnostic methods (GpA) and conventional diagnostic methods (GpB) is shown

\begin{tabular}{|c|c|c|c|c|c|}
\hline Authors & Ref. No & Sample No. & Sample Type & Sample Years & Ethnicity \\
\hline Kim et al. & 5 & 168 & CEDMG & Nov 2016-Oct 2017 & Korean \\
\hline Kim et al. & 5 & 168 & CEMRI & Nov 2016-Oct 2017 & Korean \\
\hline Song et al & 4 & 76 & DCE-MRI & Jul 2014- Feb 2015 & Korean \\
\hline Song et al & 4 & 76 & DCE-MRI+DWI & Jul 2014- Feb 2015 & Korean \\
\hline Derias et al. & 3 & 289 & MRI & Jan 2011-Dec 2013 & UK \\
\hline Bakhtawar et al. & 6 & 289 & $\mathrm{MRI}+\mathrm{MG}$ & Jan 2015-Feb 2016 & Iranian \\
\hline Bozzini et al. & 2 & 303 & USG & Oct 2000-Oct 2004 & Italy \\
\hline Bozzini et al. & 2 & 303 & USG +MG & Oct 2000-Oct 2004 & Italy \\
\hline Bozzini et al. & 2 & 303 & MG & Oct 2000-Oct 2004 & Italy \\
\hline
\end{tabular}


Combined USG + MG applications in CDMs; the sensitivity increased significantly $(p<0.05)$ compared to the single ones ${ }^{2}$ but however, in combined DCE-MRI + DWI, sensitivity was lower than DCE-MRI ${ }^{4}$ (Table 2). Among the ADMs, the highest sensitivity (98.6\%) in MBCs was obtained with diffusion weighted imaging MRI method ${ }^{4}$ and the lowest sensitivity (45.5\%) in MBCs was provided in the MG method ${ }^{2}$ (Table 2), (Figure 2). The accuracy and $\mathrm{p}$ values of invasive molecular diagnostic methods in MBCs are shown in (Table 3). ${ }^{10,11,13,17}$

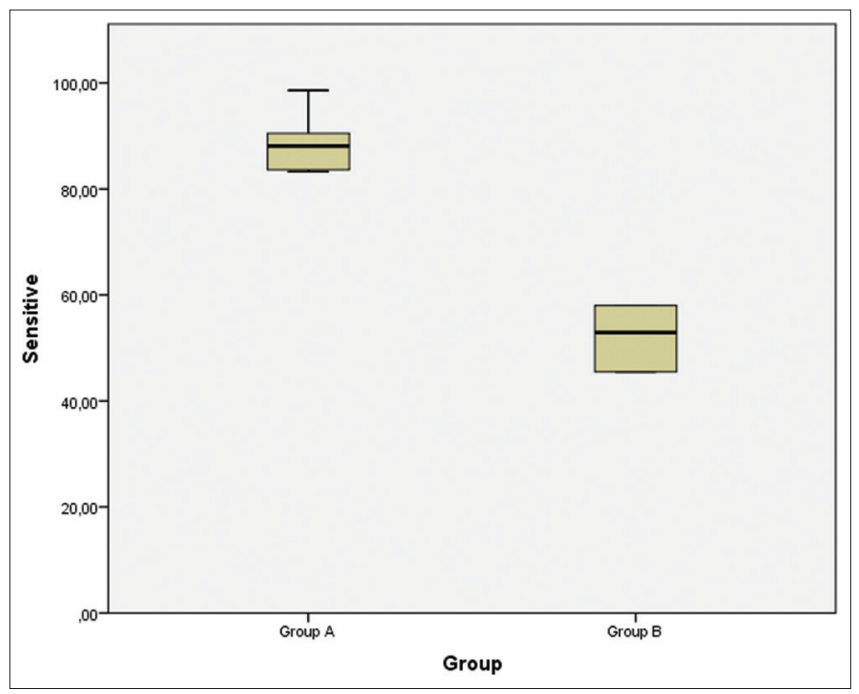

Figure 2: Forest plot of sensitivities obtained in diagnostic studies of $\mathrm{ADM}$ and $\mathrm{CM}$ in $\mathrm{MBC}$ cases

\begin{tabular}{|c|c|c|c|}
\hline \multicolumn{4}{|c|}{$\begin{array}{l}\text { Table 2: The sensitivities of advanced (GpA) } \\
\text { and conventional (GpB) diagnostic methods in } \\
\text { multiple breast cancers }\end{array}$} \\
\hline Group & $\mathbf{N}$ & $\begin{array}{c}\% \text { Sensitivity Rates } \\
\text { (Mean } \pm \text { S.D.) }\end{array}$ & $p$ \\
\hline Group A & 1066 & $88.16 \pm 4.06$ & $P \leq 0.001$ \\
\hline Group B & 909 & $52.13 \pm 5.13$ & \\
\hline
\end{tabular}

\begin{tabular}{|c|c|c|c|c|}
\hline Method & $\mathbf{N}$ & Mean \pm S.D. & Range & References \\
\hline CEDMG & 168 & $83.45 \pm 0.15$ & $83.30-83.60$ & Kim et al. \\
\hline CEDMRI & 168 & $83.45 \pm 0.15$ & $83.30-83.60$ & Kim et al. \\
\hline DCE-MRI & 76 & $98.60 \pm 0.00$ & $98.60-98.60$ & Song et al. \\
\hline $\begin{array}{l}\text { DCE- } \\
\text { MRI+DWI }\end{array}$ & 76 & $90.00 \pm 0.00$ & $90.00-90.00$ & Song et al. \\
\hline MRI & 289 & $88.10 \pm 0.00$ & $88.10-88.10$ & Derias et al. \\
\hline MRI+MG & 289 & $90.50 \pm 0.00$ & $90.50-90.50$ & $\begin{array}{l}\text { Bakhtawar } \\
\text { et al. }\end{array}$ \\
\hline USG & 303 & $52.90 \pm 0.00$ & $52.90-52.90$ & $\begin{array}{l}\text { Bozzini } \\
\text { et al. }\end{array}$ \\
\hline MG+USG & 303 & $58.00 \pm 0.00$ & $58.00-58.00$ & $\begin{array}{l}\text { Bozzini } \\
\text { et al. }\end{array}$ \\
\hline MG & 303 & $45.50 \pm 0.00$ & $45.50-45.50$ & $\begin{array}{l}\text { Bozzini } \\
\text { et al. }\end{array}$ \\
\hline Total & 1975 & $71.58 \pm 18.54$ & $45.50-98.60$ & \\
\hline
\end{tabular}

\section{DISCUSSION}

MBCs might multifocal (MF) or multicentric (MC). In a study conducted by Kanumori et al., they compared clinical findings, subtypes, estrogen receptor (ER), progestron receptor (PR), HER2, tumor size, triple negative $\mathrm{BC}$ (TNBC) types in $1231 \mathrm{UBC}, 169 \mathrm{MF}, 95 \mathrm{MC} \mathrm{BC}$ cases. $^{18}$ According to the results of their study, MCBCs showed more aggressive clinical course than MFBCs, tumor $(T)$ was larger, more common in young people, regional lymph node metastasis (RLNM) and lymphovascular invasion, they reported that RLNM is the only independent predictive factor, and because of these different properties, MF and $\mathrm{MC}$ are diseases of different biological character. ${ }^{18}$

Diagnoses are important because MBCs generally show different clinical course and survival compared to UBCs and different treatment methods are performed accordingly.

Alexander et al., in $79 \mathrm{MF}$ cases of $\mathrm{BC}$; reported that there was more tumor focus and regional lymph node metastasis in these cases due to the high tendency to lymphovascular invasion. ${ }^{19}$ In a meta analysis, Houvenaeghel et al., performed that overall survival (OS) was shorter in MFMC BCs than UBCs. ${ }^{20}$ Lang et al., in 3441 UBC and 156 MFMC BC cases; they reported that the prognosis was worse, T was greater, RLNM and Ki67 was higher in MFMC BC cases. ${ }^{11}$ Fang et al., in 10 studies $\mathrm{BC}$ compared to the data provided in 19,272 patients; they reported that local recurrence (LR) was higher in MBC cases. ${ }^{21}$

However, Karakaş et al., 323 MFMC BC; UBC and MFMC compared disease-free survival (DFS) and OS rates in BCs and reported no significant difference between them. ${ }^{22}$ Jivanovic et al., compared 5-year survival in $83 \mathrm{MBC}$ and 501 UBC cases and did not find a statistically significant difference. ${ }^{23}$ In a study by Fushimi et al., they compared $136 \mathrm{MFBC}$ cases and $598 \mathrm{UBC}$ cases, they reported that the only factor affecting prognosis was $\mathrm{T}$ size. ${ }^{24}$

One of the factors that increases the importance of diagnosing in MBC cases; is the possibility of tumoral heterogeneity and accordingly grade heterogeneity. In a study by Duan et al., 16 of 146 MFMC BC cases had tumoral heterogeneity (different molecular phenotype). ${ }^{25}$ According to the authors, OS and DFS were shorter in MFMC BC cases than in UBC cases. ${ }^{25}$

According to the authors, it has been reported that molecular phenotyping can be performed in all MBC cases and recurrence rates can be reduced and DSS can be prolonged with appropriate therapeutic approaches. ${ }^{25}$

In a study by Boros et al., in 806 MFMC BC cases; compared the histological type of the tumor with the histological grade 
and RLNM of the primary tumor from Nottingtam and found that it showed intertumoral heterogeneity. ${ }^{26}$

In a retrospective study conducted by Mosbah et al., in 205 MFMC BC cases in which 178 cases were of the same grade and $89 \%$ were of the same histological type; they reported that immunohistochemical findings were the same in $86 \%$ of cases. ${ }^{27}$ Ilic et al., reported that the immunohistochemical parameters were largely the same in 334 ILBC patients and that there was no tumor heterogeneity. ${ }^{28}$

However, Norton et al., in 11 MFMC infiltrative lobular BC (ILBC) patients with the same immunohistochemical findings (ER+, HER2-); they investigated tumor heterogeneity by examining 730 gene expression profiles, pathway activations, and 80 gene copy numbers. ${ }^{17}$ According to the results of their study, they found that 35 genes were upregulated and 34 genes were downregulated. These results demostrate that there may be heterogeneity between tumor foci in $\mathrm{MBC}$ cases and that only immunohistochemical findings are not sufficient in determining tumor heterogeneity. ${ }^{17}$

The most important factor affecting the prognosis in MBCs is tumor heterogeneity (molecular phenotype differences of the tumor) and can be seen intertumorally, intratumorally or among patients. ${ }^{17}$

In this study conducted by Norton on MF ILBC patients, more than half of the 730 gene expression analyzes detected tumoral heterogeneity in all 3 forms.

According to the results of this study, it has been reported that tumoral heterogeneity in MF ILBC patients is the most important factor hiding potential prognostic factors. ${ }^{17}$

Uthamalingam et al., studied on pathologically proven 124 $\mathrm{UBC}$ and $49 \mathrm{MF} / \mathrm{MC} \mathrm{BC}$ cases and they found that 16 of $49 \mathrm{MF} / \mathrm{MC} \mathrm{BC}$ cases showed intertumoral heterogeneity $(32.65 \%)$, and they reported that thus, each focus should be evaluated separately in $\mathrm{MF} / \mathrm{MC}$ cases. ${ }^{29}$ In a prospective study by Onisai et al., 198 cases of UBC, $31 \mathrm{MF}$, and $6 \mathrm{MC}$ were evaluated, and it was reported that staging should be done according to the most aggressive focus in MBCs. ${ }^{30}$

According to the authors, in MBC cases with intertumoral heterogeneity, inadequate treatment rates can be reduced by staging patients not according to the largest single tumor, but according to the most aggressive tumor and cumulative tumor burden. ${ }^{30}$

Desmedt et al., investigated genetic heterogeneity in 36 ductal MFBC cases, where ER and HER 2 values and grades were the same. ${ }^{31}$
Genetic heterogeneity has been shown in 12 of the cases oncological mutations. For this reason, they reported that personalized molecular diagnosis and treatment should be performed in MFBC cases. ${ }^{31}$ However, in a study by Grabenstetter et al., they could not find molecular and biological heterogeneity in 53 ipsilateral MBC cases with the same histological structure. ${ }^{32}$

Since different treatment methods are applied in MBC and UBC cases, increased sensitivity in diagnosis with ADMs and $\mathrm{MBC}$ cases; it also has a high potential to affect the choice of treatment methods.

In a retrospective study conducted by Winters et al., in 24 studies, the mean follow-up period was 59.5 months in 3537 ipsilateral MBC cases. ${ }^{33}$ They reported that there was no statistically significant difference in local recurrence rates (LRR) between patients with breast conservative therapy (BCT) and mastectomy $(\mathrm{M})$, but many of these studies were of moderate quality and biased, and thus, for the sake of clarity more randomized studies were needed. ${ }^{33}$

In a study by Massanat et al., they reported that BCT is not contraindicated in selected cases in MF/MC BCs. ${ }^{34}$ In a similar study, Koppiker et al., proposed extreme oncoplasty (EO) instead of BCT in MF/MC cases. ${ }^{35}$ Nijenhuis et al., reported that BCT may performed in most MF/MC cases. ${ }^{36} \mathrm{Tan}$ et al., performed BCT in 35 of $41 \mathrm{MF} / \mathrm{MC}$ cases, reported that only 1 patient had distant metastases after a 45 -month follow-up. ${ }^{37}$ Many authors have reported that BCT can be performed in some selected MF/MC cases. ${ }^{20,34,37,38}$ However, in a study conducted by Edwards et al., 414 of 567 cases with BCT were reviewed, and histological tumor positive margin was found in $23 \%$, and residual tumor was found in 61 cases. ${ }^{39}$

In a study by Akbulut et al., miR-429 expression was shown to increase only in MBCs, while miR-182-5p and miR-96-5p expression increased in both MBC and UBCs. ${ }^{10}$

In a study by Lameijer et al., 3.1\% cases were recalled on 130338 screening mammograms, $6.4 \%$ of them had an ipsilateral new tumor focus and $21.5 \%$ of these tumor foci were found malignity. ${ }^{40}$ Many of these cases have been reported to be $\mathrm{MF} / \mathrm{MC} \mathrm{BC} .{ }^{36}$

In another study conducted by Lai et al., 1468 BC cases were divided into 2 groups, only MG and USG were performed in GpA patients, and in $\mathrm{GpB}$ patients in addition to MG and USG, MRI was performed. ${ }^{41}$ In the same study; BCT were performed in GpA, M were performed in GpB cases. Surgical margin tumor positivity was found $9.0 \%$ in $\mathrm{GpA}$ and $5.0 \%$ in $\mathrm{GpB} .{ }^{41} \mathrm{MF} / \mathrm{MC}$ cases were significantly higher in $\mathrm{GpB}$ patients than in GpA. ${ }^{41}$ 
In this study, when sensitivities were compared in the diagnosis of MBCs, it was found that a higher sensitivity $(\mathrm{p}<0.05)$ was obtained with ADMs compared to CDMs (Table 2), (Figures 1-2).

In several studies, tumor foci were found to exhibit molecular biological heterogeneity in MBCs. ${ }^{17,26,29-31}$ According to the results obtained in this study, the most sensitive method among CDMs is the combined USG + MG method (58.0\%)(Table 2). Interestingly, however, the sensitivity in DCE-MRI + DWI combined ADM has been reported to be lower $(90.0 \%)$ than the DCE-MRI method $(98.6)^{4}$ (Table 3), (Figure 3).

According to the findings provided in these studies, tumor foci and molecular structure of all foci can be widely determined in MBCs (Table 4). According to the findings of some authors included in this study, tumoral heterogeneity could be detected in tissue by molecular marker analysis in many MBC cases with the same immunohistochemical findings. ${ }^{17,26,30,31}$ It has been demonstrated by these studies that immunohistochemical tests, which has been an important method in determining prognosis and treatment methods for many years, can not always adequately explain the molecular biological structure of the tumor. This case is an important proof that advanced diagnostic methods significantly affect prognosis and treatment. However, all of these diagnostic tests that are used to determine the molecular structure of the tumor in MBCs are invasive techniques.

In this study, a study with molecular markers in serum was not found in the MBCs in the literature. With ADMs in MBC patients; detection of tumor positivity at the surgical margin,,$^{39,41}$ local recurrence, ${ }^{21,39,40}$ possibility of another tumor focus in a different biological structure, ${ }^{19,21,26}$ or a different stage, ${ }^{25,29,30}$ the application rate of wrong or inappropriate treatment methods will decrease, ${ }^{34,41}$ personalized treatment will be provided, ${ }^{10,31}$ and the survival will be prolonged. ${ }^{11,20,24,25}$

In a study conducted by $\mathrm{Hu}$, the relationship between sociodemographic index (SDI), incidence of $\mathrm{BC}$ and mortality was examined. ${ }^{42}$ According to the results of the study; $\mathrm{BC}$ incidence and mortality have been observed to increase, especially in countries with low SDI. One of the most important reasons for this is the lack of access to $\mathrm{ADMs}$ in these countries. ${ }^{42}$

In countries with poor socioeconomic status, the diagnostic method in which the highest sensitivity and specificity rates can be achieved at the lowest cost in MBCs: MRI +MG., ${ }^{3,642}$ Based on the Markov model by Kaiser, only mammography and MRI + MG were compared for the BC diagnostic

\begin{tabular}{|c|c|c|c|c|}
\hline Biomarkers & MBC & UBC & $p$ & Refences \\
\hline $\begin{array}{l}\text { miR-429 (UR only in } \\
\text { MBC) }\end{array}$ & 26 & 31 & 0.161 & Akbulut et al. \\
\hline $\begin{array}{l}\text { miR-182-5p (UR both } \\
\text { in MBC and UBC) }\end{array}$ & 26 & 31 & $<0.001$ & Akbulut et al. \\
\hline $\begin{array}{l}\text { miR-96b-5p (UR both } \\
\text { in MBC and UBC) }\end{array}$ & 26 & 31 & 0.938 & Akbulut et al. \\
\hline $\begin{array}{l}\text { miR- } 1 \text {-3p (DR both } \\
\text { in MBC and UBC) }\end{array}$ & 26 & 31 & 0.001 & Akbulut et al. \\
\hline $\begin{array}{l}\text { miR-10b-5p (DR both } \\
\text { in MBC and UBC) }\end{array}$ & 26 & 31 & 0.001 & Akbulut et al. \\
\hline ABCC11 (UR in MBC) & 156 & 130 & $<0.05$ & Lang et al. \\
\hline $\mathrm{ABCB} 5$ (DR in MBC) & 156 & 130 & $<0.05$ & Lang et al. \\
\hline $\begin{array}{l}\text { C19orf33, C3orf52, } \\
\text { C15orf48 (UR in } \\
\text { MBC) }\end{array}$ & 156 & 130 & $<0.05$ & Lang et al. \\
\hline 4orf19 (DR in MBC) & 156 & 130 & $<0.05$ & Lang et al. \\
\hline BRCA2 (UR in MBC) & 52 & 159 & $<0.001$ & McCrorie et al. \\
\hline 35 gene (UR) & 11 & - & $<0.05$ & Norton et al. \\
\hline 34 gene (DR) & 11 & - & $<0.05$ & Norton et al. \\
\hline
\end{tabular}

DR, Downregulated; UR, Upregulated; MBC, Multiple breast cancer; UBC, Unifocal breast cancer

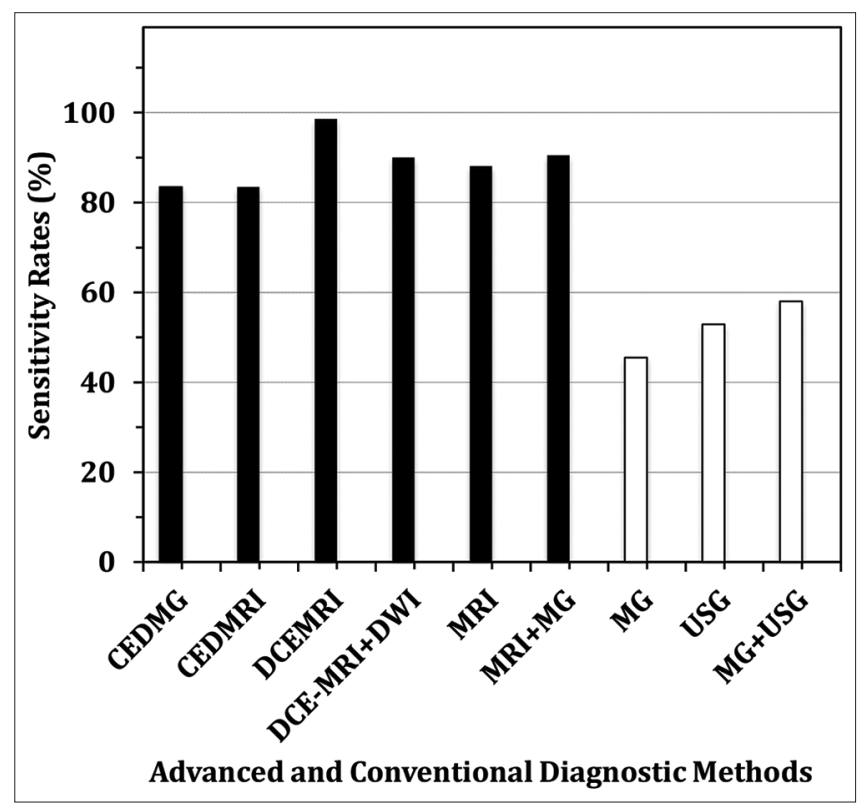

Figure 3: The comparison of percent sensitivities obtained with advanced (ADMs) and conventional diagnostic methods (CDMs) in multiple breast cancers is shown

screening test in the medium risk group, as a result, the sensitivities between 70-100\% specivities between $70-100 \%$ and overall efficiency (cost-effectiveness) were found to be between 4.68-4.70 QALYs in MRI+MG. ${ }^{43}$

In a study by Artigues for the first time on this subject; cir miRNA-30b-5p analysis in serum is the easiest to apply, noninvasive, highest sensitivity (78.3\%) and specificity (72.3\%), cost-effective diagnosis and screening method that can be effective in all types of BCs and early stages. ${ }^{44}$ Despite 
these results, this study was not included among ADMs in our study because it was not performed in MBC cases.

The limitation of our study is that a noninvasive, costeffective molecular diagnosis method that can determine tumor phenotypes in MBC patients, screening and personalized treatment programs can be applied, is not available in the literature and cannot be included in our study.

\section{CONCLUSION}

Using ADMs in BC screening programs, investigation of tumor foci by molecular methods; increases the diagnostic rates of MBCs. In MBCs, a personalized treatment plan is made with the diagnosis of the molecular structure of the tumor foci before treatment. Thus, the recurrence rates are reduced, the survival is prolonged. However, more studies are needed in order to reveal ideal molecular diagnostic methods in MBCs.

\section{Abbreviations}

ADM: Advanced diagnostic methods; BC: Breast cancer; BCT: Breast cancer therapy; CDM: Conventional diagnostic methods: DCE: Dynamic contrast enhaced MRI: DWI: Diffusion weighted imaging: EO: Extreme oncoplasty; ILBC: Infiltrative lobular breast carcinoma; LRR: Local reoccurence rate; M: Mastectomy; MBC: Multiple breast cancer; MC: Multicentric cancer; MF: Multifocal cancer; MG: Mammography; Micro-CT: Micro-computor tomography; MRI: Magnetic resonance imaging; RLNM: Regional lymph node metastasis; TNBC: Triple negative breast cancer; UBC: Unifocal breast cancer; USG: Ultrasonography; SDI: Sociodemographic index.

\section{Availability of data and material}

The datasets used and/or analyzed during the current study are available from the corresponding author on reasonable request.

\section{REFERENCES}

1. Badillo FE, Napoleone M, Ocana A, Templeton AJ, Seruga B and Mubarek MA. Effect of multifocality and multicentricity on outcome in early stage breast cancer: A systematic review and meta-analysis. Breast Cancer Res Treat. 2014;146(2):235-244. https://doi.org/10.1007/s10549-014-3018-3

2. Bozzini A, Renne G, Meneghetti L, Bandi G, Santos G, Vento AR, et al. Sensitivity of imaging for multifocal-multicentric breast carcinoma. BMC Cancer.2008;8(275). doi: 10.1186/1471-24078-275.

https://doi.org/10.1186/1471-2407-8-275
3. Derias M, Subramanian A, Allan S, Shah E, Teraifi HE and Howlett D. The Role of Magnetic Resonance Imaging in the Investigation and Management of Invasive Lobular Carcinoma-A 3-Year Retrospective Study in Two District General Hospitals. Breast J. 2016;22(4):384-389. https://doi.org/10.1111/tbj.12594

4. Song SE, Park EK, Cho KR, Seo BK, Woo OH and Jung SP. Additional Value of Diffusion-Weighted Imaging to Evaluate Multifocal and Multicentric Breast Cancer Detected Using PreOperative Breast MRI. Eur Radiol.2017;27(11):4819-4827. https://doi.org/10.1007/s00330-017-4898-5

5. Kim EY, Youn I, Lee KH, Yun JS, Park YL, Park $\mathrm{CH}$, et al. Diagnostic Value of Contrast-Enhanced Digital Mammography Versus Contrast-Enhanced Magnetic Resonance Imaging for the Preoperative Evaluation of Breast Cancer. J Breast Cancer.2018;21(4):453-462. https://doi.org/10.4048/jbc.2018.21.e62

6. Bakhtavar K, Saran M, Behzadifar M and Farsi M. Magnetic Resonance Mammography in Comparison With Mammography in the Discovery of Multifocal, Multicentric and Bilateral Lesions of Breast Cancer. Electron Physician.2017;9(8):5083-5087. https://doi.org/10.19082/5083

7. Corpo D, Tiwari A, Tang R, Griffin M, Aftreth O, Bautista P, et al. The Role of Micro-CT in Imaging Breast Cancer Specimens. Breast Cancer Res Treat.2020;180(2):343-357. https://doi.org/10.1007/s10549-020-05547-z

8. Wen G, Markey MK, Haygood TM and Park S. Model Observer for Assessing Digital Breast Tomosynthesis for Multi-Lesion Detection in the Presence of Anatomical Noise. Phys Med Biol.2018; 63(4):045017.

https://doi.org/10.1088/1361-6560/aaab3a

9. Santiago L, Whitman G, Wang C and Dogan BE. Clinical and Pathologic Features of Clinically Occult Synchronous Bilateral Breast Cancers. Curr Probl Diagn Radiol.2018;47(5):305-310. https://doi.org/10.1067/j.cpradiol.2017.08.002

10. Akbulut H, Ersoy YE, Cosskunpınar E, Gucin Z, Yıldız S, Malya FU, et al. The Role of miRNAs as a Predictor of Multicentricity in Breast Cancer. Mol Biol Rep.2019;46(2):1787-1796. https://doi.org/10.1007/s11033-019-04629-6

11. Lang Z, Wu Y, Li C, Li X, Wang X and Qu G. Multifocal and Multicentric Breast Carcinoma: A Significantly More Aggressive Tumor Than Unifocal Breast Cancer. Anticancer Res. 2017;37(8):4593-4598. https://doi.org/10.21873/anticanres. 11858

12. Lang $Z Q, W u Y Q, P a n X B, Q u$ GM and Zhang TG. The Identification of Multifocal Breast Cancer-Associated Long NonCoding RNAs. Eur Rev Med Pharmacol Sci.2017;21(24):56485654 .

13. McCrorie AD, Ashfield S, Begley A, Mcilmunn C, Morrison PJ and Boyd C. Multifocal Breast Cancers Are More Prevalent in BRCA2 Versus BRCA1 Mutation Carriers. J Pathol Clin Res.2020;6(2):146-153 https://doi.org/10.1002/cjp2.155

14. Ha R, Jin B, Mango V, Friedlander L, Miloshev V, Malak S, et al. Breast Cancer Molecular Subtype as a Predictor of the Utility of Preoperative MRI AJR Am J Roentgenol. 2015;204(6):13541360. https://doi.org/10.2214/AJR.14.13666

15. Zehni AZ, Jacob SN, Mumm JN, Heidegger H, Ditsch N, Mahner S, et al. Hormone Receptor Expression in Multicentric/Multifocal Versus Unifocal Breast Cancer: Especially the VDR Determines 
the Outcome Related to Focality. Int J Mol Sci.2019;20(22):5740. https://doi.org/10.3390/ijms20225740

16. Lang Z, Wu Y, Pan X, Qu G and Zhang T. Study of Differential Gene Expression Between Invasive Multifocal/Multicentric and Unifocal Breast Cancer. J BUON.2018;23(1):134-142.

17. Norton N, Advani PP, Serie DJ, Geiger XJ, Necela BM, Axenfeld BC, et al. Assessment of Tumor Heterogeneity, as Evidenced by Gene Expression Profiles, Pathway Activation, and Gene Copy Number, in Patients with Multifocal Invasive Lobular Breast Tumors. PLoS One. 2016;11(4). https://doi.org/10.1371/journal.pone.0153411

18. Kanumuri P,Hayse B, Killelea BK, Chagpar AB, Horowitz NR and Lannin DR. Characteristics of Multifocal and Multicentric Breast Cancers. Ann Surg Oncol. 2015;22(8):2475-2482. https://doi.org/10.1245/s10434-015-4430-6

19. Alexander M, Gonzales GA, Malerba S, Hochman T, Goldberg JD and Darvishian F. Multifocal Invasive Ductal Cancer: Distinguishing Independent Tumor Foci From Multiple Satellites Int J Surg Pathol. 2017;25(4):298-303. https://doi.org/10.1177/1066896916676586

20. Houvenaeghel G, Tallet A, Jalaguier-Coudray A, Cohen M, Bannier M, Fara CJ, et al. Is Breast Conservative Surgery a Reasonable Option in Multifocal or Multicentric Tumors? World J Clin Oncol. 2016;7(2):234-242. https://doi.org/10.5306/wjco.v7.i2.234

21. Fang $M$, Zhang $X$, Zhang $H$, Wu K, YuY and Sheng $Y$. Local Control of Breast Conservation Therapy Versus Mastectomy in Multifocal or Multicentric Breast Cancer: A Systematic Review and Meta-Analysis. Breast Care (Basel).2019;14(4):188-193. https://doi.org/10.1159/000499439

22. Karakaş $\mathrm{Y}$, Dizdar $\mathrm{O}$, Aksoy $\mathrm{S}$, Hayran $\mathrm{M}$ and Altundağ $\mathrm{K}$. The Effect of Total Size of Lesions in Multifocal/Multicentric Breast Cancer on Survival. Clin Breast Cancer. 2018;18(4):320-327. https://doi.org/10.1016/j.clbc.2017.11.002

23. Jovanovic LD, Karanikolic A, Bojic T, Djordjevic $M$ and Marinkovic M. Characteristics and Outcomes of Patients With Multifocal/Multicentric and Unifocal Breast Cancer. J BUON. 2017;22(3):652-657.

24. Fushimi A, Yoshida A, Yagata $\mathrm{H}$, Takahashi O, Hayashi $\mathrm{N}$, Suzuki K, et al Prognostic Impact of Multifocal and Multicentric Breast Cancer Versus Unifocal Breast Cancer. Surg Today. 2019;49(3):224-230.

https://doi.org/10.1007/s00595-018-1725-9

25. Duan YS, Mao QX, Li LF, Sun YD, Wang $L$ and Cui SD. [Intertumoral Heterogeneity of Molecular Phenotype and Analysis of Prognosis in Multifocal and Multicentric Breast Cancer]. Zhonghua Zhong Liu Za Zhi.2016;38(11):833-838.

26. Boros M, Podoleanu C, Georgescu R, Moldovan C, Molnar C and Stolnicu S. Multifocal/multicentric Breast Carcinomas Showing Intertumoural Heterogeneity: A Comparison of Histological Tumour Type and Nottingham Histological Grade of Primary Tumour and Lymph Node Metastasis. Pol J Pathol. 2015;66(2):125-132. https://doi.org/10.5114/pjp.2015.53008

27. MosbahR, RouzierR, Guinebretiere JM,FalcouMC,StevensDand Hequet D. Pathological Characteristics of Both Tumors in Bifocal and Bicentric Breast Cancer. Anticancer Res. 2015;35(9):51115116.

28. Ilic IR, Petrovic A, Zivkovic VV, Randjelovic PJ, Stojanovic NM, Radulovic NS, et al. Immunohistochemical Features of Multifocal and Multicentric Lobular Breast Carcinoma. Adv Med Sci.2017;62(1):78-82. https://doi.org/10.1016/j.advms.2016.07.003

29. Uthamalingam $P$, Rangarajan $B$, Sekar $P$ and Mehta S. Impact of Focality on Prognostication of Early and Operable Breast Carcinomas of No Special Type. J Cancer Res Ther. 2019;15(5):1024-1030.

https://doi.org/10.4103/jcrt.JCRT_804_17

30. Onisai M, Dumitru A, Iordan I, Alius C, Teodor O, Alexandru A, et al. Synchronous Multiple Breast Cancers-Do We Need to Reshape Staging? Medicina (Kaunas). 2020;56(5)230. https://doi.org/10.3390/medicina56050230

31. Desmedt C, Fumagalli D, Pietri E, Zoppoli G, Brown D, Zainal SN, et al. Uncovering the Genomic Heterogeneity of Multifocal Breast Cancer. J Pathol. 2015;236(4):457-466. https://doi.org/10.1002/path.4540

32. Grabenstetter A, Brogi E, Chou JF, Morrow M, Dickler M, Norton L, et al. Multifocal/Multicentric Ipsilateral Invasive Breast Carcinomas With Similar Histology: Is Multigene Testing of All Individual Foci Necessary? Ann Surg Oncol. 2019;26(2):329-335.

https://doi.org/10.1245/s10434-018-6866-y

33. Winters ZE, Horsnell J, Elvers KT, Maxwell AJ, Jones LJ, Shaaban AM, et al. S1ystematic Review of the Impact of BreastConserving Surgery on Cancer Outcomes of Multiple Ipsilateral Breast Cancers. BJS Open. 2018;2(4):162-174. https://doi.org/10.1002/bjs5.53

34. Masannat YA, Agrawal A, Maraqa L, Fuller M, Down SK, Tang SK, et al. Multifocal and Multicentric Breast Cancer, Is It Time to Think Again? Ann R Coll Surg Engl. 2020;102(1): 62-66. https://doi.org/10.1308/rcsann.2019.0109

35. Koppiker CB, Noor AU, Dixit S, Busheri L, Sharan G, Dhar U, et al. Extreme Oncoplastic Surgery for Multifocal/Multicentric and Locally Advanced Breast Cancer. Int J Breast Cancer.2019: Article ID 4262589.

https://doi.org/10.1155/2019/4262589

36. Nijenhuis MV and Rutgers EJ. Conservative Surgery for Multifocal/ Multicentric Breast Cancer. The Breast. 2015; 24:595-599. https://doi.org/10.1016/j.breast.2015.07.023

37. Tan M, Sitoh NY and Sim AS. Breast Conservation Treatment for Multifocal and Multicentric Breast Cancers in Women With Small-Volume Breast Tissue. ANZ J Surg. 2017;87(6)E5-E10. https://doi.org/10.1111/ans.12942

38. Tan MP: A Novel Segment Classification for Multifocal and Multicentric Breast Cancer to Facilitate Breast-Conservation Treatment. Breast J. 2015;21(4):410-417. https://doi.org/10.1111/tbj.12424

39. Edwards SB, Leitman IM, Wengrofsky A, Giddins MJ, Harris E and Mills CB. Identifying Factors and Techniques to Decrease the Positive Margin Rate in Partial Mastectomies: Have We Missed the Mark? Breast J. 2016;22(3):3030-3039. https://doi.org/10.1111/tbj.12573

40. Lameijer JR, Coolen AM, Nederend J, Voogd AC, Heijnen T and Duijin LE. Frequency and Characteristics of Additionally Detected Ipsilateral Breast Lesions Following Recall at Screening Mammography. Breast. 2018; 42:94-101. https://doi.org/10.1016/j.breast.2018.08.104

41. Lai HW, Chen CJ, Lin YJ, Chen SL, Wu HK, Wu YT, et al. Does Breast Magnetic Resonance Imaging Combined With Conventional Imaging Modalities Decrease the Rates of Surgical Margin Involvement and Reoperation? A Case-Control Comparative Analysis. Medicine (Baltimore).2016;95(22):e3810. https://doi.org/10.1097/MD.0000000000003810 
42. Hu K, Ding P, WuY, Tian W, Pan T and Zhang S. Global patterns and trends in the breast cancer incidence and mortality according to sociodemographic indices: an observational study based on the global burden of diseases. BMJ Open.2019;9(10). https://doi.org/10.1136/bmjopen-2018-028461

43. Kaiser CG,Dietzel M, Mattihias TV and Froelich F. Costeffectiveness of MR-mammography vs. conventional mammography in screening patients at intermediate risk of breast cancer - A model-based economic evaluation.Eur $J$ Radiol.2021;136:109513.

https://doi.org/10.1016/j.ejrad.2020.109355

44. Artigues AA, Garrido-Cano I, Simon S, Ortega B, Moragon S, Lameirinhas V, et al. Circulating miR-30b-5p levels in plasma as a novel potential biomarker for early detection of breast cancer. ESMO Open. 2021;6(1).

https://doi.org/10.1016/j.esmoop.2020.100039

\section{Author's contribution:}

HZA and NO - Concept and design of the study, prepared first draft of the study, interpreted the results, reviewed the literature and prepared the Manuscript statistically analysed and interpreted, preparation of manuscript and revision of the manuscript.

\section{Work attributed to:}

Girne American University Faculty of Medicine Girne/Cyprus

\section{Orcid ID:}

Prof Hasan Zafer Acar I- (1) https://orcid.org/0000-0001-6435-8720

Prof Nazmi Özer - (D) https://orcid.org/0000-0002-2630-741X

Source of funding: None, Conflict of Interest - None. 